\title{
Surgical outcome of ipsilateral fracture of the femur and tibia in adults (floating knee)
}

\author{
Tumbal SV ${ }^{1}$, Kothadia $S^{2}$ \\ ${ }^{1}$ Dr. Shirish V. Tumbal, Associate Professor, ${ }^{2}$ Dr. Swapnil Kothadia, Assistant Professor, both authors are affiliated with \\ Department of Orthopaedics, Ashwini Rural Medical College, Hospital \& Research Centre, Kumbhari, Solapur, \\ Maharastra, India.
}

Correspondence Author: Dr. Swapnil Kothadia, Assistant Professor, Department of Orthopaedics, Ashwini Rural Medical College, Hospital \& Research Centre, Kumbhari, Solapur, Maharashtra, India.

\begin{abstract}
Background: Due to the large number of accidents, femur and tibia for Ipsilateral injuries eventually occur; floating injuries are likely to take place. The study was conducted to evaluate the results of surgery for adults with ipsilateral femoral and tibial fractures. Methodology: The study included 15 patients aged 20 to 60 . According to Fraser et al, fractures are classified as Type I (5), IIa (3), IIb (4) and IIc (3). Femur fractures were treated using locked intramedullary nails plate-screws, or dynamic condylar screws. Tibia fractures were treated with an external fixator (in open fractures), or plate-screws, and locked intramedullary nailing. The average follow-up period is 2.1 years. Investigations for chest, pelvis, affected lower limbs, including joints and other bone injury were investigated by x-ray. Result: The mean age of the study group was 39.46 years. The time taken from admission to surgery is 2 days ( 1 to 11 days). The average followup time was 23.5 months (from 20 to 25 months). Most of the cases showed better results (66.7\%) in extent of bonyunions, followed by good (20\%), acceptable (6.7\%) and poor (6.7\%), according to the criteria of Karlstrom. Conclusion: Injury and fractures (openness, straightening, congestion) are predictive factors in the floating knee. The complete adequacy of critical injury-related conflicts includes fractures and post-surgical rehabilitation.
\end{abstract}

Keywords: Adult, Floating Knee, Ipsilateral fracture, Tibia

\section{Introduction}

McBride and Blake, are first introduced the concept of floating knee injury [1]. The femur and tibiafor Ipsilateral fractures are known as "floating knee", with metaphyseal, diaphyseal, and intra-articular fractures $[2,3]$. Many authors highlighted the increased risk of complications and long-term injuries [4,5]. The findings suggest that by identifying the exact fracture of both bones, it gives the excellent results [6,7]. Due to the high risk, these injuries were the result of brutal injuries.

Due to the fracture of many bones, management has become difficult for the same end. As population growth increases with increased traffic accidents, the frequency of floating injuries is high in such incidents. Fractures can be simple diaphyseal to complex articular types.One of the biggest studies on 222 patients, reported in the literature studied for 11 years [8].

Manuscript Received: $10^{\text {th }}$ April 2019

Reviewed: $20^{\text {th }}$ April 2019

Author Corrected: $28^{\text {th }}$ April 2019

Accepted for Publication: $2^{\text {nd }}$ May 2019
There are life-threatening lesions on the chest, abdomen, and pelvis. The management of these injuries is different and the chances of increasing risk fat embolism are more [9]. And they are involvedin damaging the arteries. Due to early mobilization and stabilizing of both fractures, the limb produces the best clinical results. Facilitate to make use of antegrade intra-meduallary nail of femur and tibia and radiolucent operating room table for surgical stabilization of floating knee factures. In some cases these wounds are likewise connected with collateral ligament and meniscal wounds. The most widely recognized complications, for example, compartment disorder, loss of knee development, difficulty to analyze knee ligament injury, and the prerequisite for removal.

Outcome would be better with less complication, when one or both are intraarticular and both fractures are diaphyseal [2]. The present study was undertaken to assess patients' results after surgery of Floating Knee injuries and the prognostic factors for these injuries. 


\section{Materials and Methods}

Type of study: Prospective study

Study duration: Jan 2018 to December 2018

Place of study: Tertiary care centre

The present study conducted on 15 patients aged between 20 to 60 years. According to Fraser and al [7], types of fractures are classified as: Type I (8) Type IIA (2) IIb (4) and IIC (1). Initial management and immobilizing the extremity support given by Thomas splint and auxiliary study helping to identify different wounds.Further investigation, chest, pelvis, affected lower limbs, including joints and other bone injury were investigated by x-ray.In the present study, according to the classification of Gustilo-Anderson, classifications of Open fractures are done [10]. For open fractures, debridement of wound, antibiotic therapy and tetanus immunization were initiated.

\section{Selection criteria}

\section{Inclusion criteria}

1. Aged between 20 and 60 years

2. Patients who had ipsilateral femoral and tibialfractures

\section{Exclusion criteria}

1. Aged less than 20 and more than 60 years

2. Children who wound the floating knee

\section{Surgical procedure}

Pre-Operational Assessment and Management: In high velocity injuries, suspicion of trauma related and other organ involvement. For prevention of fat embolism, the patient is closely monitored. In addition, the patient is administered in an intensive care unit and surgical fixation was postponed wherever fat embolism observed. In OT, open fractures are debrided when the patient becomes stable. If possible, the injury is closed loosely, otherwise it is still open for secondary suturing.

Used locked intramedullary nail, (Type I: 8 and Type IIA: 2) with screws in 5 cases (Type IIb: 4 and IIC: 1), femur fractures were performed. In one case of open fracture, fracture of the tibia is treated with external fixator, three flat screws (type IIA, type IIC:1) or locked intramedullary nail (Type- I:7 \& Type-IIb: 4).

When the patient is hemodynamically stable and suitable for operation and can be treated, the operation is carried out both. Before the tibia fractures, femur fractures were repaired.

The most common form of use for both fractures is intramedullary nail.External fixation was the definitive management in open tibia fracture.

Assessment of Post-surgical and follow-up: During later treatment, Thromboprophylaxis was initiated and given for 5 days post operatively for all patients.

After surgery, physiotherapy was initiated for one week. For $1 \frac{1}{2}$ months, followed by weighted by a wooden wheel, weightless walking is permissible.

After clinical and radiological unionconfirmation, full weight intake is acceptable. Regularly, evaluations of postoperative and surgical treatment are performed.

Until the combination of boney union (clinics and radiation), patients are monitored periodically. After confirmation of bony union, functional evaluations and final results were measured using the Karlstromcriterion [10]. 


\section{Clinical and Radiological Photographs}

Case-1
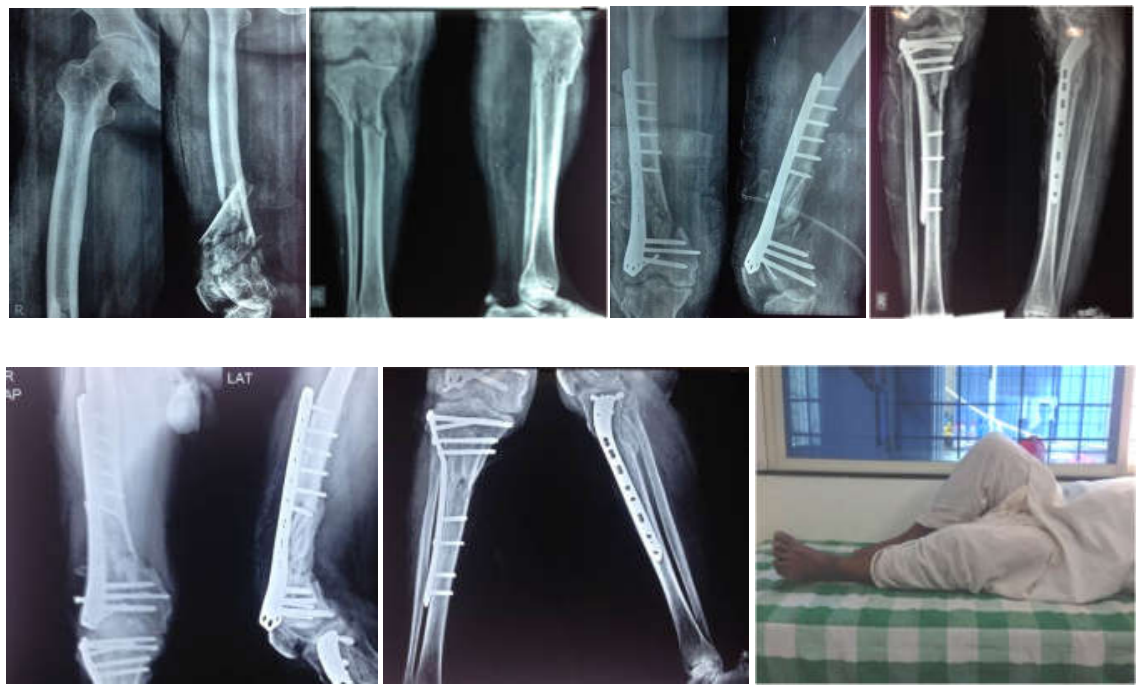

Fig.-1: Pre-operative X-ray, Immediate post operative X-ray, Two years follow up-excellent knee function

\section{Case-2}
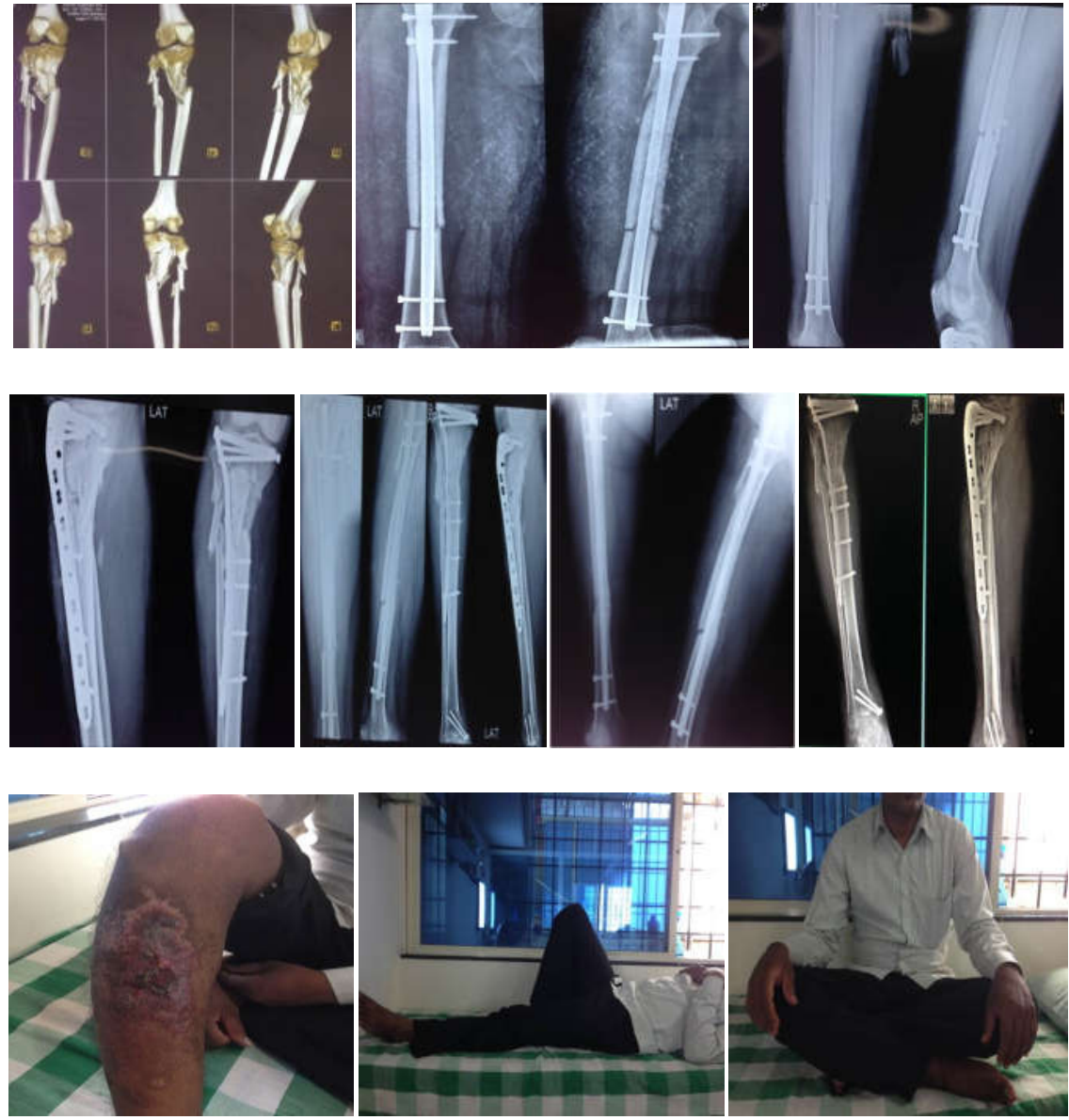

Fig.-2: Pre-operative X-ray, Immediate post operative X-ray, Follow up-excellent knee function and images of the patient after healing 


\section{Original Research Article}

\section{Case-3}

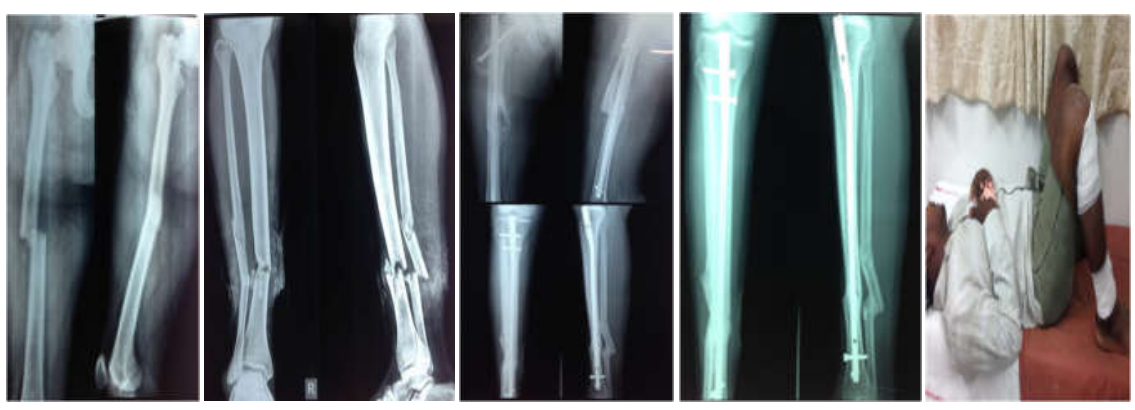

Fig.-3: Pre-operative X-ray, Immediate post operative X-ray, Follow up-excellent knee function, Images of the patient after healing

\section{Case-4}
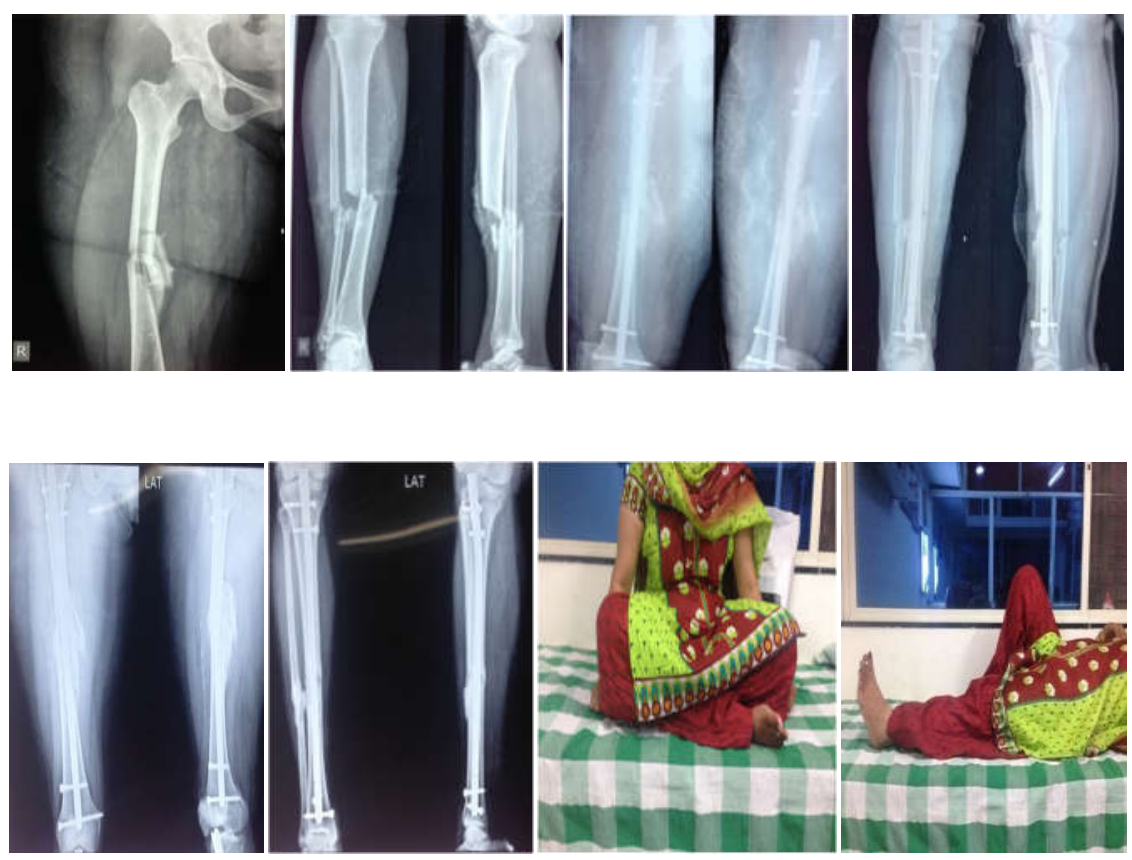

Fig.-4: Pre-operative X-ray, Immediate post operative X-ray, Follow up-excellent knee function, images of the patient after healing

Statistical methods: The collected data entered in Microsoft excel. Tables and graphs were generated by using Microsoft excel. Descriptive statistics such as mean, SD and percentage was used to present the data.

\section{Result}

Male patient dominance is more (93.3\%). The mean age of the patientswas 39.46 years (Table-1). From the surgical procedure, the average duration is 2 days (between 1 and 11 days). On 9 patients, intramedullary nails for both joints were applied. For the remaining six patients, the combination of preventing compression, clamping, exterior Tibia bacterial repairs and bowl support was done.Complications were observed in two patients in the knee delayed the integration of Tibia with one patient and one on one patient.

The additional procedure is a cure under knee surgery and strength in a patient with unions. Patients with slow unions demanded tooth movements and removal of external graft and fractures. These fractures have changed to one after these interventions. Infection on the surface is related to the location of the external needles that are successfully administered by pain and antibiotic care. The average follow-up period was 23.5 months ( 20 to 26 months). 
Original Research Article

Table-1: Basic characteristics.

\begin{tabular}{|c|c|c|}
\hline Characteristics & Number & Percentage \\
\hline Age & & 20.0 \\
\hline$<20$ & 3 & 46.7 \\
\hline $20-40$ & 7 & 20.0 \\
\hline $40-60$ & 3 & 13.3 \\
\hline$>60$ & 2 & 93.3 \\
\hline Sex & 14 & 6.7 \\
\hline Male & 1 & 80.0 \\
\hline Female & & 20.0 \\
\hline Side involved & 12 & \\
\hline Right & 3 & \\
\hline Left & & \\
\hline
\end{tabular}

Table-2: Functional outcome.

\begin{tabular}{|c|c|}
\hline Karlstrom criteria & Cases \% \\
\hline Excellent & $10(66.66)$ \\
\hline Good & $3(20)$ \\
\hline Acceptable & $1(6.66)$ \\
\hline Poor & $1(6.66)$ \\
\hline Total & 15 \\
\hline
\end{tabular}

By using the Karlstrom's criteria, functional assessment and final outcome was assessedand it was found that, majority of the cases are shown excellent (66.6\%) in extent of bony union followed by good (20\%), acceptable $(6.6 \%)$ and poor $(6.6 \%)$

\section{Discussion}

The study showed that, riders had to press firmly to the slopes of the front seats just before the clash, as their feet crashed under delayed forces which greatly affected by the impact. By striking railroad tracks, most of the pedestrians often caught at a specific distance from the point of impact and injuries [4]. In another study of 222 cases, due to traffic accidents, floating knee injury were found and most of these injuries to the head, chest and abdomen which are life-threatening [8].

Adamson et al. reported that, $71 \%$ of the key cases related to disability, $21 \%$ were as vascular injuries [11]. In the study, five other deaths ranging from $5 \%$ to $15 \%$, reflecting the severity of the related injuries [2]. To determine if there is a severe head or chest injury, one should pay close attention to the patient. Such injuries should be prioritized given to extremity injuries for the treatment. There are various variants for floating knee control. The study revealed that one or more fractures of surgical fixation were valuable in controlling the whole limbs for multiple fractures at the end [4]. Since it is unlikely these patients develop hard or short of the knee and stay in the hospital and get out of work for less time than compared to therapeutic and internal fixation of fractures that should be done, whereverpossible [12]. In another study, floating knee remedies have received using addictive, conservative and surgical fixation and observed that, fractures of the femoral and tibial zones has been made addictive to internal sources of information; the duration of the treatment was about eight weeks earlier than the conservative group [5].

In another study, floating knee patients which were treated with closed intramedullary nailing with ender nails was achieved onan average, 10.3 weeks for femoral unions and 18 weeks for tibial unions [9]. In another study, for patients with a retrograde femoral tibial, intramedullary nail through a $4 \mathrm{~cm}$ medial parapatellar incision, the average time to the union of the femoral was 14.7 weeks and tibial fractures were 23 
weeks and further recommended, this approach be the perfect treatment option [13]. Researcher's recommended early-stage stimulation, surgical stabilizing fractures gives the best results [2]. Theodoratus et al, introduce intramedullary nailing and recommended this treatment with exception of $3 \mathrm{~B}$ grade and $\mathrm{C}$ open fractures gives best result [14]. For blotting and stain with traditional antegrade nailing by singleincision technique, and found that there is less time for surgery and anesthesia that reduces blood loss. Shiedts et al. reported it is possible to increase the severity of the fat embolism when both are treated with reamed nails [15].

Another study reported that, there wereinstances of instability in $18 \%$, while knee ligament laxitywas in $53 \%$ of the patients. Most suffer from discomfortof a break of the anterior cruciate ligament; with or without compromising other ligaments.In addition, they reported that, kneeligament injuryisfound to be more common in knee injury than the isolated femoral fractures and recommend that all the assessments be cautions [16]. In one more study reported that $\backslash$, in floating knee, a knee ligament injury was found up to $50 \%$ [17].

According to a study reported by Gregory et al and Ostrum, fixations of both fractures are achieved excellent results by doing intramedullary nailing. The authors used retrograde nailing for the femur, although all nails areantegrade in the study. If necessary, no knee problem would be possible to repair the knee ligament easily, as the slimming scars are slowed, the regeneration of the knee ligament makes it difficult $[13,18]$. The main indications of joint damage to fractures for poor performance are high scores for bone wounds and severity of soft tissue injury [18-20].

The study suggested identifying the prognosis factors which affects on the final outcome, a proper preassessment system would be executes by taking account of main factors such as at the time of injury-smoking status, severity scores, open fractures, segmental fractures and comminution [21].For primary surgery, delay duration, long-term surgery, exposure to medication, and late treatment, subsequent injuries play an important role in the patient's initial results [22].

When treated with intramedullary nailing to both fractures, the chances of getting the best result would be greater. Compared to other modalities, these patients return to normal levels of their activity quite earlier. At the initial injury, due to soft tissue injury and communication, the fractures were treated by external

\section{Original Research Article}

fixation.In the current study, three patients showed poor results. Among the two patients, two patients with knee fractures were suffering from knee pain and knee pain, while one patient was treated with external attachment with a $3 \mathrm{~B}$ spinal cord.

\section{Conclusion}

From the present study, it is concluded that, floating knee injuries are a complex injuries group requiring careful evaluation of the detection of poor prognostic factors and associated injuries. Repair of surgical fixation of the fractures is recommended by a complete surgical planning and rehabilitation.

What this Study adds to existing knowledge? Literature on the surgical outcomes of Ipsilateral Fracture of the Femur and Tibia in Adults (Floating Knee) would help to complete adequacy of critical injury-related conflicts includesfractures and postsurgical rehabilitation, which makes a meaningful adding in existing literature by conducting our study.

Conflict of interest: None declared.

Funding: Nil, Permission from IRB: Yes

\section{References}

1. Blake R, McBryde A Jr. The floating knee: Ipsilateral fractures of the tibia and femur. South Med J. 1975 Jan;68 (1):13-6.

2. Lundy DW, Johnson KD. "Floating knee" injuries: ipsilateral fractures of the femur and tibia. J Am Acad Orthop Surg. 2001 Jul-Aug;9(4):238-45.

3. Jeong GK, Pettrone SK, Liporace FA, Meere PA. Floating total knee: ipsilateral periprosthetic fractures of the distal femur and proximal tibia after total knee arthroplasty. The Journal of arthroplasty. 2006 Jan 1;21 (1): 138-40.

4. HAYES JT. Multiple fractures in the same extremity: some problems in their management. Surg Clin North Am. 1961 Oct;41:1379-88.

5. Omer GE Jr, Moll JH, Bacon WL. Combinded fractures of the femur and tibia in a single extremity. Analytical study of cases at Brooke General Hospital from 1961-to1967. J Trauma. 1968 Nov;8(6):1026-41.

6. Bansal VP, Singhal V, Mam MK, et al. The floating knee. 40 cases of ipsilateral fractures of the femur and the tibia. Int Orthop. 1984;8(3):183-7.DOI:10.1007/bf 00269914 


\section{Original Research Article}

7. Chhina JS, Kapila R. Ipsilateral Fractures Of Femur \& Tibia-A Clinical Study. Indian Journal of Orthopaedics. 1999 Jul 1;33(3):159.

8. Fraser RD, Hunter GA, Waddell JP. Ipsilateral fracture of the femur and tibia. J Bone Joint Surg Br. 1978 Nov;60-B(4):510-5.

9. Behr JT, Apel DM, Pinzur MS, et al. Flexible intramedullary nails for ipsilateral femoral and tibial fractures. J Trauma. 1987 Dec;27(12):1354-7.

10. Gustilo RB, Anderson JT. Prevention of infection in the treatment of one thousand and twenty-five open fractures of long bones: retrospective and prospective analyses. J Bone Joint Surg Am. 1976 Jun;58(4):453-8.

11. Adamson GJ, Wiss DA, Lowery GL, et al. Type II floating knee: ipsilateral femoral and tibial fractures with intraarticular extension into the knee joint. J Orthop Trauma. 1992;6(3):333-9.

12. Ratliff AH. Fractures of the shaft of the femur and tibia in the same limb. Proc R Soc Med. 1968 Sep;61 (9): 906-8.

13. Ostrum RF. Treatment of floating knee injuries through a single percutaneous approach. Clin Orthop Relat Res. 2000 Jun;(375):43-50.

14. Theodoratos G, Papanikolaou A, Apergis E, et al. Simultaneous ipsilateral diaphyseal fractures of the femur and tibia: treatment and complications. Injury. 2001 May;32(4):313-5.

15. Schiedts D, Mukisi M, Bouger D, et al. [Ipsilateral fractures of the femoral and tibial diaphyses]. Rev ChirOrthop Reparatrice Appar Mot. 1996;82(6):535-40.
16. Szalay MJ, Hosking OR, Annear P. Injury of knee ligament associated with ipsilateral femoral shaft fractures and with ipsilateral femoral and tibial shaft fractures. Injury. 1990 Nov;21(6):398-400.

17. Paul GR, Sawka MW, Whitelaw GP. Fractures of the ipsilateral femur and tibia: emphasis on intraarticular and soft tissue injury. J Orthop Trauma. 1990;4(3):309-14.

18. Gregory P, DiCicco J, Karpik K, et al. Ipsilateral fractures of the femur and tibia: treatment with retrograde femoral nailing and unreamed tibial nailing. $\mathrm{J}$ Orthop Trauma. 1996;10(5):309-16.

19. Yokoyama K, Tsukamoto T, Aoki S, et al. Evaluation of functional outcome of the floating knee injury using multivariate analysis. Arch Orthop Trauma Surg. 2002 Nov;122(8):432-5. Epub 2002 Apr 25.

20. Arslan H, Kapukaya A, Kesemenli CC, et al. [The floating knee in adults: twenty-four cases of ipsilateral fractures of the femur and the tibia]. Acta Orthop Traumatol Turc. 2003;37(2):107-12.

21. Arslan H, Kapukaya A, Kesemenli CC, Necmioğlu S, Subaşi M, Coban V. The floating knee in adults: twenty-four cases of ipsilateral fractures of the femur and the tibia. Acta orthopaedica et traumatologica turcica. 2003;37(2):107-12.

22. Hung SH, Lu YM, Huang HT, et al. Surgical treatment of type II floating knee: comparisons of the results of type IIA and type IIB floating knee. Knee Surg Sports Traumatol Arthrosc. 2007 May; 15 (5): 578-86. Epub 2007 Jan 4. DOI: 10.1007/ s00167-0060252-1.

\section{How to cite this article?}

Tumbal SV, Kothadia S. Surgical outcome of ipsilateral fracture of the femur and tibia in adults (floating knee). Surgical Update: Int J surg Orthopedics. 2019;5(2):87-93.doi:10.17511/ijoso.2019.i02.04. 